\title{
Sinking rates of phytoplankton assemblages in the Weddell Sea marginal ice zone
}

\author{
Tina O. Johnson ${ }^{1} \&$ Walker O. Smith, Jr. ${ }^{2}$ \\ ' Botany Department, University of Tennessee, Knoxville, Tennessee 37996, USA \\ ${ }^{2}$ Botany Department and Graduate Program in Ecology, University of Tennessee, Knoxville, Tennessee 37996, USA
}

\begin{abstract}
Sinking rates of phytoplankton assemblages from the Weddell Sea marginal ice zone were measured during a cruise in November-December 1983. A homogeneous sample method (SETCOL) was used to measure sinking rates which permitted rates of various parameters of particulate matter to be determined simultaneously. Parameters assayed in this study included chlorophyll $a$, phaeophytin, biogenic silica, particulate carbon, particulate nitrogen, and for certain stations, numbers of diatoms. Sinking rates varied within each measurement but exhibited the following trends: phaeophytin $>$ biogenic silica $>$ particulate carbon $>$ diatoms $>$ particulate nitrogen $>$ chlorophyll $a$. Sinking rates as determined by chlorophyll a ranged from 0 to $2.73 \mathrm{~m} \mathrm{~d}^{-1}(\overline{\mathrm{x}}=0.89$ ), i.e. are similar to those reported for temperate and subpolar regions of the ocean. Phytoplankton assemblages from pycnoclines generally sank slower than those from the surface; differences in seawater density and viscosity between the 2 depths could account for no more than $5 \%$ of the observed differences. Samples placed in the dark tended to sink faster than those placed in surface light. The reported rates represent the settling of suspended microparticulates within the upper water column in the absence of turbulence and should not be extrapolated to estimate the vertical flux of particulates from the euphotic zone.
\end{abstract}

\section{INTRODUCTION}

Sedimentation of phytoplankton cells and larger particles such as fecal material is primarily responsible for the vertical flux of organic matter in the oceans and for the loss of biogenic material from the euphotic zone. It is clear that phytoplankton do not simply sink as predicted by Stokes' equation but are influenced by a number of factors, e.g. cellular morphology, physiological state, density and viscosity of the medium, and local vertical and horizontal water movements (e.g. Smayda 1970). In addition, ambient light intensity (Bienfang et al. 1983, Bienfang 1985) and nutrient concentrations (Bienfang et al. 1982, Bienfang \& Harrison 1984) also affect sinking rates. The degree to which all of these factors influence sinking rates of phytoplankton assemblages is presently uncertain.

Recently a relatively simple technique has been developed to measure sinking rates of particulate matter in the field (Bienfang 1981). Quantitative measurements have been made in tropical (Bienfang \& Harrison 1984, Bienfang 1985), temperate (Bienfang \& Harrison 1984), and subpolar regions (Bienfang 1984, Jacques \& Hoepffner 1984). Sinking rates of suspended

(c) Inter-Research/Printed in F. R. Germany microparticulates range from ca 0 to $1.0 \mathrm{~m} \mathrm{~d}^{-1}$; i.e. they are much lower than earlier estimates (Smayda 1970). Bienfang (1985) found rates near zero in tropical regions dominated by small flagellated species; these rates were influenced by prevailing environmental conditions. Despite the apparently low sinking rates, passive sinking of phytoplankton has been shown to have a large impact on the composition of phytoplankton communities (Trimbee \& Harris 1984).

Phytoplankton dynamics during an ice-edge bloom in the Ross Sea revealed depletion of dissolved silicic acid from the upper water column closely matched by the appearance of biogenic particulate silica (Nelson \& Smith 1986). Silicon conservation implied low loss rates of biogenic silica during this study, i.e. loss of diatomaceous material via passive sinking or grazing and subsequent flux of fecal material was minimal. However, diatoms make up an overwhelming proportion of the biogenic material in the sediments beneath the bloom, and sediment accumulation rates indicate that a large proportion (ca $80 \%$ ) of the surface siliceous production is being delivered to the sediments (Nelson et al. unpubl.). Material collected by sediment traps in this region consists primarily of single phyto- 
plankton cells that apparently have not been ingested by herbivores (Dunbar et al. 1985). Furthermore, there is a strong taxonomic correlation between species found in the ice-edge bloom (Smith \& Nelson 1985) and those in the sediments (Truesdale \& Kellogg 1979). Microscopic examination of diatoms in water-column samples indicates the frustules to be robust compared to temperate forms, as is often the case for polar diatoms (Smayda pers. comm.). So the Ross Sea marginal ice zone appears to be the site of active production and flux of biogenic material; what role passive sinking of phytoplankton plays in the flux of material to the benthos in this and other marginal ice zones is unknown. The purpose of this study was to quantitatively estimate sinking rates of microparticulates within the marginal ice zone of the Weddell Sea and to attempt to relate these rates to the spatial and temporal variability in environmental parameters.

\section{MATERIALS AND METHODS}

Sinking rates of phytoplankton assemblages were measured during a cruise to the marginal ice zone of the Weddell Sea on board the RV Melville in November-December 1983. These measurements were part of the Antarctic Marine Ecosystem Research at the Ice-Edge Zone (AMERIEZ) program. Sinking rate determinations were conducted at 27 stations (Fig. 1). At each station density and fluorescence profiles were determined using a Neil Brown CTD-system coupled with a SeaTech in situ fluorometer. Specially designed PVC samplers were used to sample discrete depths throughout the euphotic zone; samplers were modified to minimize the loss of rapidly sinking particulates.
Sinking rates of particulate matter were determined using a homogeneous sample method called SETCOL (Bienfang 1981). With this method a plexiglass column surrounded by a water jacket through which surface seawater flowed was filled with an initially homogeneous water sample and allowed to settle undisturbed for a known period of time. The entire column was held in a 2-dimensional gimbal apparatus (Fig. 2) to eliminate turbulence induced by the ship's roll, and placed on deck and exposed to ambient light intensities. After settling, the upper portion of the column was slowly drained by opening the side port; water from the column's lower portion $\left(V_{s}\right)$ was collected through the bottom port. Particulate concentrations were measured initially from the homogenous sample and after the incubation from the volume in the lower portion of the column. Increases in the particulate matter concentrations due to settling generally were large; for example, in the surface vs pycnocline experiments chlorophyll a increased by about $430 \%$ (incubations ranging from 3.0 to $6.0 \mathrm{~h}$ ). The calculated sinking rate is a function of the biomass which accumulated in the column's lower portion relative to the total biomass initially within the column, as well as the length of the column and the settling interval, according to the formula

$$
\psi=\mathrm{f}_{\mathrm{s}} \mathrm{L} / \mathrm{t}
$$

where $\psi=$ sinking rate; $f_{s}=$ fraction of initial biomass that sank; $\mathrm{L}=$ length of column $(0.59 \mathrm{~m}$ in this study); $\mathrm{t}=$ settling interval. A detailed theoretical analysis of this method is presented in Bienfang (1981).

In the method's original description the increase in chlorophyll a (or other particulate matter parameter) during the settling interval was corrected for by conducting separate incubations under similar environ-

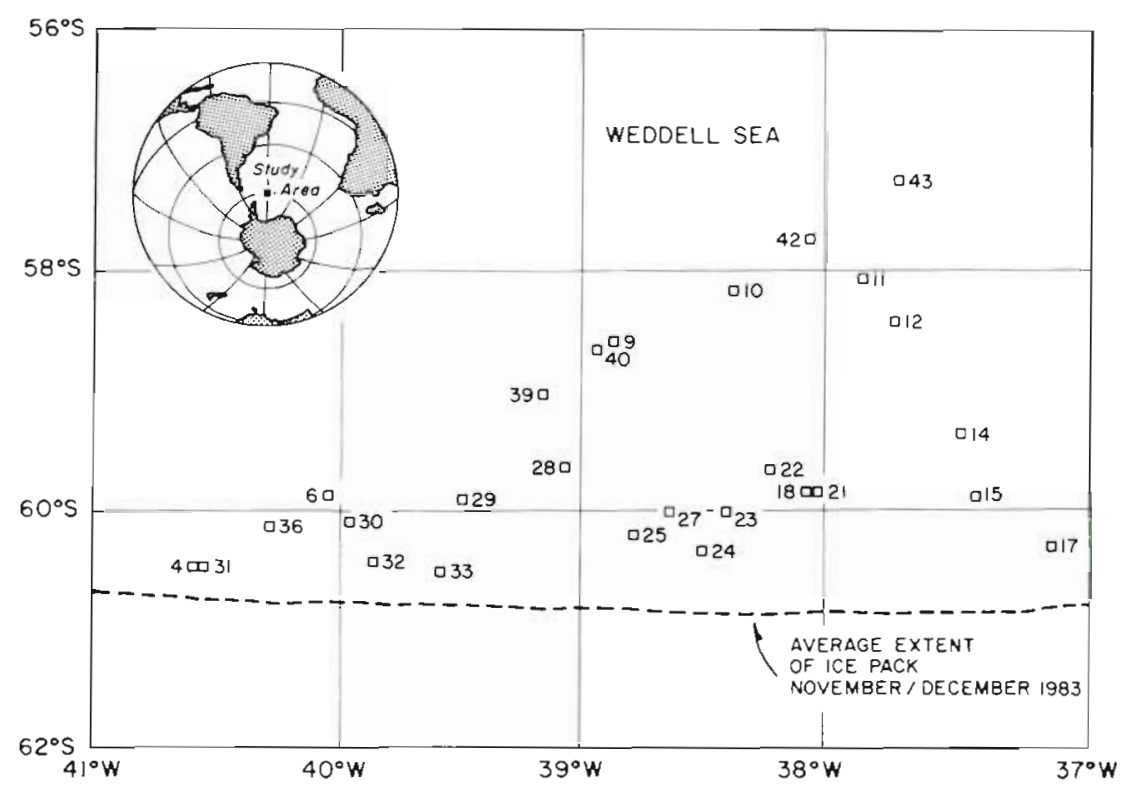

Fig. 1. Lacations of stations at which sinking rates were determined in the Weddell Sea during Nov-Dec 1983 


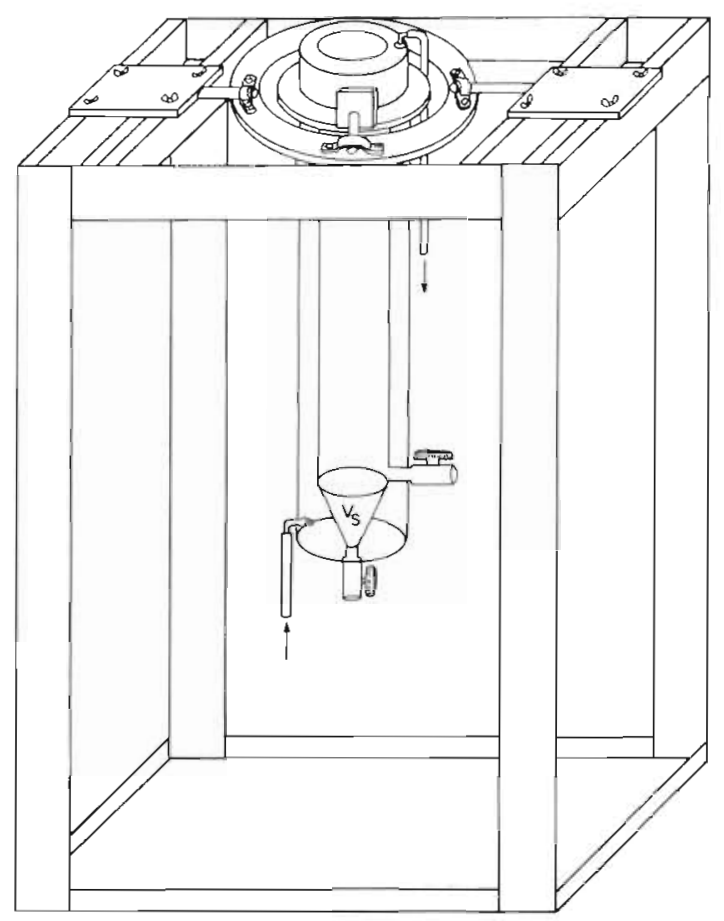

Fig. 2. Diagram of SETCOL column placed in 2-dimensional gimbal apparatus. Length of column $=59 \mathrm{~cm}$, inner diameter $=9 \mathrm{~cm}$, total volume $=4.0 \mathrm{l}$, settled volume $=350 \mathrm{ml}$

mental conditions (Bienfang 1981). We found in Antarctic waters that such an incubation was not needed, because the time constants of adaptation and/ or growth at the low temperatures encountered were much less than the rates of increase due to sinking. Values reported herein are therefore not corrected for any change due to growth or adaptation within the settling interval.

By using the SETCOL method, sinking rates of various particulate matter parameters could be determined. Parameters analyzed were chlorophyll a, phaeopigment, biogenic silica, particulate carbon, particulate nitrogen, and for some stations, numbers of diatom cells. After extraction in $90 \%$ acetone pigments were analyzed fluorometrically on a Turner Designs Model 10 fluorometer, and concentrations of chlorophyll a and phaeopigments determined from measurements before and after acidification. The fluorometer was standardized using known quantities of chlorophyll a (Sigma). Particulate carbon and nitrogen were determined by filtering known quantities of water through precombusted $\left(4 \mathrm{~h}\right.$ at $\left.450^{\circ} \mathrm{C}\right)$ Whatman $\mathrm{AH}-930$ glass fiber filters and rinsing with $5 \mathrm{ml} 0.01 \mathrm{~N}$ $\mathrm{HCl}$ in seawater to remove inorganic carbonates. Separate filters placed directly under other filters served as blanks. All filters were dried at $60^{\circ} \mathrm{C}$ and combusted using a Perkin-Elmer elemental analyzer Model 240 B. Biogenic silica was measured by filtering known sea- water volumes through a $0.6 \mu \mathrm{m}$ Nuclepore filter; the filters were dried at $60{ }^{\circ} \mathrm{C}$, converted to silicic acid by sodium hydroxide digestion (Paasche 1973) and the reactive silicate concentrations determined spectrophotometrically (Parsons et al. 1984). Whole water samples were preserved in $2 \%$ glutaraldehyde for floristic analyses, and diatoms were enumerated by settling a known volume and counting on an inverted microscope (Hasle 1978).

In addition to sinking rate determinations of surface samples, a comparison of sinking rates from the surface and pycnocline was made at selected stations. Using 2 columns, one was filled with water from the pycnocline (sample depth determined from the CTD-trace) and the other with surface seawater. The 2 columns were treated in the same manner in order to determine if sinking rates varied between these 2 depths. Other experiments examined the effect of light by using 2 columns, one of which was completely darkened, and measuring the settling velocity of particles from a single, homogenous sample. The time allowed for settling in these experiments was 4 to $6 \mathrm{~h}$.

Experiments were also conducted to determine what effect, if any, the duration of settling may have on the calculated sinking rates. The 2 columns were filled from the same water sample, with each of the columns having a different settling interval.

\section{RESULTS}

The study area was characterized by elevated levels of chlorophyll a (generally $>1 \mu \mathrm{g} \mathrm{l}^{-1}$ ) confined within $250 \mathrm{~km}$ from the ice edge (Smith \& Nelson 1986). Nutrients were always extremely abundant (e.g. the lowest nitrate concentration encountered was $21.2 \mu \mathrm{M}$; Gordon et al. unpubl.) and depth of the mixed layer averaged $57 \mathrm{~m}$. The diatoms in the ice-free waters were dominated by Thalassiosira spp. $(20$ to $30 \mu \mathrm{m}$ in diameter), with significant numbers of Nitzschia spp. present. Vertical profiles of chlorophyll a indicated a subsurface chlorophyll maximum at most stations at an average depth of $55 \mathrm{~m}$.

Sinking rates estimated from the SETCOL method were dependent on the parameter used to measure particulate matter changes. In general, the following trend in sinking rates was noted (Table 1): $\psi_{\text {Phaeo }}>\psi_{\mathrm{BSi}}$ $>\psi_{\text {POC }}>\psi_{\text {Diat }}>\psi_{\text {PN }}>\psi_{\mathrm{Chl}}$. Negative values were considered to be zero. Although sinking rate averages for these parameters are similar, within each experiment there was usually considerable variation in the calculated velocities. For example, at Station 18, $\psi_{\mathrm{POC}}=1.77, \psi_{\mathrm{BS}}=0.91, \psi_{\mathrm{Phaeo}}=0.82, \psi_{\mathrm{PN}}=0.75$, and $\psi_{\mathrm{Chl}}=0.27 \mathrm{~m} \mathrm{~d}^{-1}$. There were also considerable variations in sinking rates among stations, possibly 
Table 1. Sinking rate ranges and means $\left(\mathrm{m} \mathrm{d}^{-1}\right)$ of partıculate matter parameters for all experiments

\begin{tabular}{|lcc|}
\hline Parameter & Range & Average \\
\hline Phaeopigment & 0 to 5.47 & 1.17 \\
Biogenic silica & 0 to 3.44 & 1.11 \\
Particulate carbon & 0 to 4.93 & 1.08 \\
Diatom cell numbers & 0 to 2.88 & 0.91 \\
Particulate nitrogen & 0 to 3.30 & 0.89 \\
Chlorophyll a & 0 to 2.73 & 0.89 \\
\hline
\end{tabular}

due to temporal and spatial variability in biological and physical parameters. No statistical analyses were conducted on the means because such a comparison of means would be confounded by other parameters (e.g. station location, time of sampling, etc.) and potentially lead to erroneous conclusions.

To test if sinking rates were different between samples from the surface and those from within the pycnocline, 8 independent determinations were made using paired columns. For 5 of these experiments, sinking rates (as determined from chlorophyll a changes) were decidedly lower at the pycnocline than at the surface (Table 2).

Sinking rates (as calculated from chlorophyll a changes) were somewhat higher for samples settled in darkness when compared to those settled in sunlight for 5 of the 7 experiments (Table 3). No attempt was

Table 2. Sinking rates $\left(\mathrm{m} \mathrm{d}^{-1}\right)$ determined from chlorophyll a changes for surface vs pycnocline experiments

\begin{tabular}{|ccc|}
\hline Station & Surface & Pycnocline \\
\cline { 2 - 3 } 9 & 0.95 & 0.62 \\
11 & 0.87 & 1.53 \\
24 & 0.53 & 0.50 \\
28 & 0.62 & 0.56 \\
30 & 1.37 & 0.61 \\
31 & 1.78 & 0.55 \\
32 & 1.55 & 0.81 \\
39 & 2.46 & 0.19 \\
\hline
\end{tabular}

Table 3. Sinking rates $\left(\mathrm{m} \mathrm{d}^{-1}\right)$ determined from chlorophyll a changes for 100 vs $0 \%$ surface irradiance experiments

\begin{tabular}{|lll|}
\hline Station & $100 \%$ & $0 \%$ \\
\hline 12 & 0.69 & 1.06 \\
14 & 0.30 & 0.65 \\
17 & 0.50 & 0.52 \\
18 & 0.27 & 0.56 \\
21 & 0 & 0.28 \\
22 & 0.69 & 0.65 \\
23 & 0.27 & 0.37 \\
\hline
\end{tabular}

made to simulate the in situ light cycle (i.e. samples were collected regardless of the time of day and immediately placed in the columns), so that it is uncertain if a true diurnal variation in sinking rates can be predicted from these experiments. Nonetheless, the trend was for greater sinking rates in samples settled in darkness, similar to the observations of Bienfang (1985)

The duration of settling exhibited a marked effect on the sinking rates. In samples with shorter settling times, sinking rates (as calculated from chorophyl a changes) were consistently higher in each of the 4 experiments (Table 4).

Table 4. Sinking rates $\left(\mathrm{m} \mathrm{d}^{-1}\right)$ as determined from chlorophyll a changes for the time-course experiments

\begin{tabular}{|ccc|}
\hline Station & Settling interval & Sinking rate \\
\hline \multirow{2}{*}{27} & $3 \mathrm{~h}$ & 0.81 \\
& $6 \mathrm{~h}$ & 0.56 \\
33 & $2.5 \mathrm{~h}$ & 1.06 \\
& $6 \mathrm{~h}$ & 0.55 \\
36 & $1 \mathrm{~h}$ & 2.14 \\
& $2 \mathrm{~h}$ & 1.53 \\
$40-3$ & $2 \mathrm{~h}$ & 2.73 \\
& $4 \mathrm{~h}$ & 1.13 \\
\hline
\end{tabular}

\section{DISCUSSION}

These observations represent the first sinking rates reported from marginal ice zones. Previously reported measurements of sinking rates from other areas of the ocean include flagellate-dominated subarctic assemblages $\left(\psi_{\mathrm{Ch}}=0.07 \mathrm{~m} \mathrm{~d}^{-1}\right)$ and diatom-dominated assemblages from the same area $\left(\psi_{\mathrm{chl}}=0.43 \mathrm{~m} \mathrm{~d}^{-1}\right.$; Bienfang 1984). A diatom-dominated temperate (Friday Harbor, Washington, USA) assemblage exhibited a sinking rate of $0.96 \mathrm{~m} \mathrm{~d}^{-1}$ (Bienfang \& Harrison 1984). The only measurements of sinking rates in Antarctic waters were reported by Jacques \& Hoepffner (1984) who found sinking rates (based on chlorophyll a changes) near the Kerguelen Islands from 0.10 to $0.52 \mathrm{~m} \mathrm{~d}^{-1}$. The mean sinking rate we determined for the Weddell Sea marginal ice zone was $0.89 \mathrm{~m} \mathrm{~d}^{-1}$, which is somewhat higher than in most of the previous studies, but our range encompassed values reported from other areas.

Variation in sinking rates has also been observed in subarctic phytoplankton assemblages (Bienfang 1984). In that study, as in ours, chlorophyll-based sinking rates were the lowest of all parameters measured. These variations may be attributed to a number of factors. Firstly, small nanoplankton (flagellates, small 
diatoms) would sink more slowly than aggregates or larger diatoms, and hence - if they dominated the assemblage - would result in low sinking rates (when based on chlorophyll changes). Secondly, different phytoplankton species exhibit diverse elemental and pigment ratios, so the relative contributions of each would vary in space and time. Finally, particulate matter determinations include detrital material along with phytoplankton, and it is known that amorphous detrital aggregates sink faster than viable phytoplankton cells (McCave 1975). Because chlorophyll should be the biomass parameter most representative of living phytoplankton, our results confirm that living phytoplankton sink more slowly than detrital material. Particulate carbon determinations include all organic material collected on a filter, and hence encompass an extremely heterogeneous group of particles. Given the variable nature of the quantity and form of detritus in a region with highly variable production and phytoplankton biomass, it is not surprising that sinking rates as determined from particulate carbon measurements are variable relative to those derived from chlorophyll a. That is, large amounts of detritus occurring as fecal material would most likely result in elevated carbonbased sinking rates; in contrast, if significant amounts of heterotrophic flagellates and bacteria were present, sinking rates derived from particulate carbon determinations could be less than those calculated from chlorophyll changes.

Sinking rates determined from phaeopigments also were higher than those of chlorophyll a. Because phaeopigments are primarily produced by grazing of herbivores (Shuman \& Lorenzen 1975) and because fecal pellet sinking rates are on the order of $100 \mathrm{~m} \mathrm{~d}^{-1}$ (Fowler \& Small 1972), it might be expected that the difference between phaeopigment and chlorophyllbased sinking rates would be greater. However, discrete water samplers seldom collect faster sinking particles (McCave 1975); therefore, phaeopigments collected in water bottles most likely arise via microzooplankton grazing (Welschmeyer \& Lorenzen 1985) and exist as small, amorphous particles. Alternatively, the phaeopigments may have been derived from fragmentation of larger fecal pellets. Regardless of the source, the particles containing phaeopigments are largely detrital and contribute to the faster sinking components of the particulate matter sampled.

Sinking rates from pycnoclines were lower than those from the surface. These differences cannot be solely accounted for by differences in seawater density (a function of primarily salinity in this area) and viscosity (controlled by temperature) between these 2 depths. The theoretical differences in sinking rates that should result from physical factors can be approximated from Stokes' equation by substituting appropri- ate density and viscosity values from both the surface and pycnocline, and assuming that the biologically controlled factors (e.g. cell size, species composition, density of cells per se) remain constant. Such calculations indicate that the density and viscosity changes between the 2 depths can account for no more than $5 \%$ of the differences observed experimentally (Table 2). For example, at Station 11 sinking rates determined by chlorophyll were almost twice as high at the surface relative to the pycnocline ( 1.53 and $0.87 \mathrm{~m} \mathrm{~d}^{-1}$ ); however, differences in temperature between surface and pycnocline $\left(0.24\right.$ and $0.20 \mathrm{C}^{\circ}$, respectively) and in sigma-t (27.45 and 27.64, respectively) account for less than $1 \%$ of the difference in sinking rates between these 2 depths. Therefore, other factors that influence phytoplankton sinking rates must account for these differences. Growth at low light levels characteristic of pycnoclines observed during this study (generally less than $5 \%$ of surface irradiance) may result in decreased sinking rates (Bienfang et al. 1983). Elevated nutrient concentrations that often occur directly below and within pycnoclines may be related to decreased phytoplankton sinking rates near this depth (Hobson \& Lorenzen 1972, Venrick et al. 1973). However, nutrients were consistently high throughout the upper $100 \mathrm{~m}$ (Smith \& Nelson 1986) so that a nutrient effect on sinking rates would not be expected. The observed decrease in sinking rates within the water column is undoubtedly biologically mediated; however, the mechanism of this control remains uncertain.

Despite the difficulty of extrapolating sinking rate measurements to estimates of particulate matter flux, the losses through the base of the euphotic zone (when measured) can be compared to the integrated primary productivity to estimate the percentage of daily production lost via sinking from the euphotic zone. Such a calculation is valid only when sinking rates (and the biological processes which influence them) do not vary widely within the euphotic zone. We feel this is most likely to occur in an area undergoing intense vertical mixing. When we selected stations with deep vertical mixing and minor sinking rate variations within the upper layer, we found that from 8 to $12 \%$ of the daily primary productivity was lost from the euphotic zone, similar to Bienfang's (1984) estimate for a subarctic system. We emphasize, however, that these values must be viewed as an extremely crude flux approximation in view of the rate variations in space and time; however, the calculation does characterize the role which passive sinking played relative to other loss processes (particularly grazing and fecal pellet production) in the turnover of microparticulates in the euphotic zone during this study.

The results from the experiments comparing sinking rates of phytoplankton settled in darkness to those 
settled in surface light conditions suggest that light influences sinking rates. It has been observed that night-time sinking rates were about twice as high as day-time rates for subtropical assemblages (Bienfang 1985). However, cultures of the diatom Ditylum brightwelli grown on an 8:16 light: dark cycle exhibited lower sinking rates during darkness (Anderson \& Sweeney 1977, 1978). Possibly, laboratory manipulations do not mimic the natural environment closely; hence laboratory results cannot be compared directly to in situ experiments. It is also possible that Ditylum is not characteristic of diatoms found in natural assemblages. Our results are comparable to Bienfang's and indicate that light levels do affect sinking rates.

For unialgal cultures, settling of phytoplankton cells should not be influenced by the duration of settling lat least not until the point where most cells have reached the column's lower portion; Bienfang 1981). However, in natural systems, where particulate matter includes detritus as well as a heterogeneous phytoplankton assemblage (e.g. diatoms, microzooplankton, bacteria, and both auto- and heterotrophic flagellates), differences in settling times may result in differences in sinking rates of the total particulates (Fig. 3). That is, shorter settling times will measure primarily the faster sinking fraction of the particulates, including very large cells or colonies, large detrital particles, or those phytoplankton that sink rapidly due to some physiological factor. Longer settling times will give lower

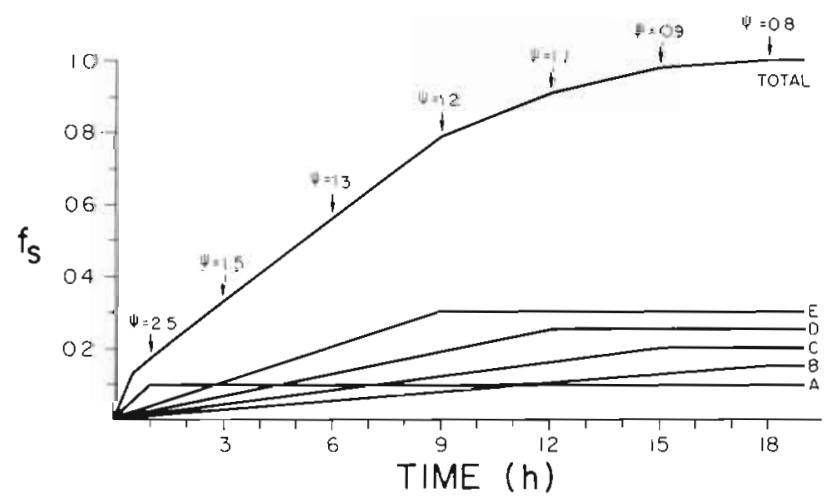

Fig. 3. Hypothetical plot of the fraction of settled biomass $\left(f_{s}\right)$ vs time for various components $(\mathrm{A}, \mathrm{B}, \mathrm{C}, \mathrm{D}$, and $\mathrm{E})$ of particulate matter. These components represent 10,15,20,25, and $30 \%$ of the total particulates and exhibit sinking rates $(\psi)$ of $14.2,0.8,0.9,1.2$, and $1.6 \mathrm{~m} \mathrm{~d}^{-1}$, respectively. As a result of the different sinking rates, $100 \%$ of the particulates contained in each component reaches the column's lower portion $\left(V_{s}\right)$ at different times $(1,18,15,12$, and $9 \mathrm{~h}$, respectively). Component $\mathrm{A}$ is representative of faster sinking particles such as detritus while $B$ to E represent slower sinking groups of particulates. The plot of $\mathrm{f}_{\mathrm{s}}$ vs time for the combined total particulates illustrates the effect that the settling interval may have on the calculated sinking rate, i.e. for settling periods of $1 \mathrm{~h}$ vs $3 \mathrm{~h}$, the calculated sinking rates for the total particulates are 2.5 and $1.5 \mathrm{~m} \mathrm{~d}^{-1}$, respectively sinking rates, which result from the cumulative impact of slower sinking particles such as pico- and nanoplankton. Therefore when using the SETCOL method to measure sinking rates of natural phytoplankton assemblages, the duration of settling can influence the rates measured.

The SETCOL method is a simple and reliable method for estimating sinking rates of suspended microparticulates (i.e. those collected by discrete water samplers) independent of turbulent motion. Our results show that sinking rates are not constant but vary considerably within the euphotic zone. These variations appear to be largely biologically mediated (physical factors such as viscosity and seawater density induce minor variations when sinking rates are approximated by Stokes' Law) and are controlled only slightly by physical conditions. As a result of these variations, it would be difficult to predict particulate fluxes from the euphotic zone, since variations in space and time occur. Furthermore, because these sinking rates represent sinking in absence of turbulence, net particle movement in the upper ocean layers will be a function of water motion as well as passive sinking. Nonetheless, because sinking potentially results in a significant quantitative and qualitative loss of phytoplankton from surface populations, an analysis of sinking rates in different systems may lead to further understanding of the dynamics of plankton communities.

Acknowledgements. This research was supported by the National Science Foundation (Grant Numbers DPP-8218758 and DPP-8420213). We acknowledge J. Ahern, J. Jennings and M. Sparrow (Oregon State University) for assistance in the field. B. Huber and D. Mountain supplied temperature salinity, density and fluorescence data, and J. Ahern performed the biogenic silica analyses. W. Brown drafted the figures. The authors also thank Drs. P. K. Bienfang, T. J. Smayda and D. M. Nelson for constructive comments on an earlier draft of this paper.

\section{LITERATURE CITED}

Anderson, L. W. J., Sweeney, B. M. (1977). Diel changes in sedimentation characteristics of Ditylum brightwelli changes in cellular lipid and effects of respiratory inhibitors and ion-transport modifiers. Limnol. Oceanogr 22: $539-552$

Anderson, L. W. J., Sweeney, B. M. (1978). Role of inorganic ions in controlling sedimentation rate of a marine centric diatom Ditylum brightwelli. J. Phycol. 14: 204-214

Bienfang, P. K. (1981). SETCOL - a technologically simple and reliable method for measuring phytoplankton sinking rates. Can. J. Fish. Aquat. Sci. 38: $1289-1294$

Bienfang, P. K. (1984). Size structure and sedimentation of biogenic microparticulates in a subarctic ecosystem. J Plankton Res. 6: 985-995

Bienfang, P. K. (1985). Size structure and sinking rates of various microparticulate constituents in oligotrophic Hawaiian waters. Mar. Ecol. Prog. Ser 23: 143-151 
Bienfang, P. K., Harrison, P. J. (1984). Sinking-rate response of natural assemblages of temperate and subtropical phytoplankton to nutrient depletion. Mar. Biol. 83: 293-300

Bienfang, P. K., Harrison, P. J., Quarmby, L. M. (1982). Sinking rate response to depletion of nitrate, phosphate and silicate in four marine diatoms. Mar. Biol. 67: 295-302

Bienfang, P. K., Szyper, J. P., Laws, E. (1983). Sinking rate and pigment responses to light-limitation of a marine diatom: implications to dynamics of chlorophyll maximum layers. Oceanologica Acta 6: 55-62

Dunbar, R. B., MacPherson, A. J., Wefer, G. (1985). Water column particulate flux and seafloor deposits in the Bransfield Strait and southern Ross Sea, Antarctica. Antarct. J. U.S. 208: in press

Fowler, S. W., Small, L. F. (1972). Sinking rates of euphausiud fecal pellets. Limnol. Oceanogr. 17: 293-296

Hasle, G. R. (1978). Settling, the inverted-microscope method. In: Sournia, A. (ed.) Phytoplankton manual - monographs on oceanographic methodology, No.6. UNESCO, Paris, p. 88-96

Hobson, L. A., Lorenzen, C. J. (1972). Relationships of chlorophyll maxima to density structures in the Atlantic Ocean and Gulf of Mexico. Deep Sea Res. 19: 297-306

Jacques, G., Hoepffner, N. (1984). Sinking rates of subantarctic neritic phytoplankton. C. r. hebd. Séanc. Acad. Sci. Paris, Serie III 299: 581-584

McCave, I. N. (1975). Vertical flux of particles in the ocean. Deep Sea Res. 22: 491-502

Nelson, D. M., Smith, W. O. (1986). Phytoplankton bloom dynamics of the western Ross Sea ice edge. II. Mesoscale cycling of nitrogen and silica. Deep Sea Res. 33 (in press)

Paasche, E. (1973). Silicon and the ecology of marine plankton diatoms. I. Thalassiosira pseudonana (Cyclotella nana) grown in a chemostat with silicate as the limiting nutrient. Mar. Biol. 19: 117-126

Parsons, T. R., Maita, Y., Lalli, C. M. (1984). A manual of chemical and biological methods for seawater analysis. Pergamon Press, Oxford

Shuman, F. R., Lorenzen, C. J. (1975). Quantitative degradation of chlorophyll by a marine herbivore. Limnol. Oceanogr. 20: $580-586$

Smayda, T. J. (1970). The suspension and sinking of phytoplankton in the sea. Oceanogr. mar. Biol. A. Rev. 8: $353-414$

Smith, W. O., Nelson, D. M. (1985). Phytoplankton bloom produced by a receding ice edge in the Ross Sea: spatial coherence with the density field. Science 227: 163-166

Smith, W. O., Nelson, D. M. (1986). The importance of iceedge phytoplankton blooms in the Southern Ocean. Bioscience 36 : 251-257

Trimbee, A. M., Harris, G. P. (1984). Phytoplankton population dynamics of a small reservoir: use of sedimentation traps to quantify the loss of diatoms and recruitment of summer bloom-forming blue-green algae. J. Plankton Res. 6: $897-917$

Truesdale, R. S., Kellogg, T B. (1979). Ross Sea diatoms: modern assemblage distributions and their relationship to ecologic, oceanographic, and sedimentary conditions. Mar. Micropaleontol. 4: 13-31

Venrick, E. L., McGowan, J. A., Mantyla, A. W. (1973). Deep maxima of photosynthetic chlorophyll in the Pacific Ocean. Fish. Bull. U.S. 71: 41-52

Welschmeyer, N. A., Lorenzen, C. J. (1985). Chlorophyll budgets: zooplankton grazing and phytoplankton growth in a temperate fjord and the Central Pacific Gyres. Limnol. Oceanogr. 30: 1-21

This article was presented by Dr N. S. Fisher; it was accepted for printing on July 31, 1986 